\title{
Nota introdutória ao núcleo temático - A educação na Europa do Sul: Constrangimentos e desafios em tempos incertos
}

\author{
Leonor L. Torres ${ }^{\mathrm{i}}$ \\ Universidade do Minho, Portugal \\ Mariana Gaio Alvesii \\ Universidade Nova de Lisboa, Portugal
}

Os sistemas educativos da Europa do Sul deparam-se com alguns desafios que, não sendo historicamente novos na sua natureza, apresentam hoje diferentes nuances ao nível do seu alcance e impacto social. Os processos de democratização escolar desenvolvidos nas últimas décadas parecem ser agora reequacionados e, em alguns contextos, travados pela progressiva penetração de uma ideologia modernizadora inspirada na nova gestão pública, que pressiona os sistemas educativos à produção de resultados. Estamos em presença de uma tensão explícita entre as lógicas democratizadoras e as lógicas performativas, que se sustenta numa matriz política comum, mas que se materializa de modos diferenciados nos vários contextos socioculturais (cf. Branden, Avermaet, \& Houtte, 2011).

A força desta tensão, que aponta para sentidos de educação nem sempre conciliáveis, faz-se sentir nos diferentes patamares do sistema educativo, desde o nível da formulação transnacional das políticas educativas (plano mega), ao espaço nacional de recontextualização e operacionalização de modos de regulação da educação (plano macro), passando ainda pelos modos de organização e gestão das organizações escolares (plano meso) e, por fim, pelo próprio coração dos processos e dinâmicas de escolarização (plano micro). Do centro às periferias do sistema educativo é hoje visível que 
esta tensão atravessa os vários patamares e níveis de escolarização, exigindo igualmente um olhar multifocado a partir de variadas escalas de observação e suportado em referenciais teóricos plurais (Torres \& Palhares, 2014).

Portugal e Espanha partilham características comuns no plano dos processos de implantação e desenvolvimento dos respetivos sistemas educativos, defrontando-se atualmente com alguns dilemas decorrentes da aproximação tardia à modernidade educativa ocidental. A análise dos constrangimentos políticos, sociais e culturais que assolam as sociedades contemporâneas da Europa do Sul (com particular incidência nos países ibéricos) e dos consequentes desafios que se colocam à reconfiguração dos sistemas educativos constituiu o objetivo central que presidiu à organização da $I^{\text {a }}$ Conferência Ibérica de Sociologia da Educação, realizada nos dias 9, 10 e 11 de Julho de 2015, na Faculdade de Ciências Sociais e Humanas da Universidade Nova de Lisboa. Este encontro científico significou uma oportunidade valiosa para aprofundar o conhecimento e o debate sobre este tema, para além de abrir a possibilidade de criação de redes de interconhecimento e parcerias de colaboração entre sociólogos da educação portugueses e espanhóis.

Desdobrando-se em nove linhas temáticas, a conferência procurou mapear o conhecimento produzido, numa perspetiva comparada, em torno de duas questões centrais: "Que instrumentos teóricos e metodológicos estão os sociólogos da educação portugueses e espanhóis a mobilizar no sentido de dar conta destes constrangimentos e desafios educativos? Que objetos de pesquisa privilegiam e que enfoques valorizam?" (Alves, Torres, Dionísio, \& Abrantes, 2016: xxiv). Ao longo dos três dias de trabalho foram apresentadas um total de 130 comunicações em vários formatos (sessões virtuais, simpósios e sessões temáticas), maioritariamente de autores portugueses e espanhóis provenientes de diferentes regiões geográficas e de diversas instituições, muito embora o evento contasse igualmente com sociólogos de outros países, designadamente do Brasil, Chile, Venezuela, Estados Unidos da América, Irlanda e México.

Este núcleo temático integra cinco textos selecionados do conjunto de quase setenta originalmente entregues à Comissão Organizadora da conferência para publicação nas respectivas atas. A seleção dos cinco textos 
decorreu da articulação de alguns critérios: i) a inclusão de trabalhos que permitissem uma perspetiva abrangente sobre os países ibéricos ou sobre algumas das suas regiões, realizados em ambos os países, por forma a favorecer o conhecimento e o confronto das respetivas realidades educativas; ii) a exclusão de relatos de trabalhos em curso, optando-se por textos suportados em pesquisas suficientemente consolidadas para permitir o esboço de conclusões (ainda que as mesmas possam assumir-se como provisórias); iii) a prioridade conferida às linhas temáticas mais destacadas na "call for papers" da conferência; iv) a solidez científica dos textos, designadamente no que respeita à clareza e pertinência dos objetivos, à adequação da metodologia da pesquisa adotada e à relevância da revisão de literatura e dos resultados alcançados. Os cinco artigos selecionados foram submetidos como textos originais à Revista Portuguesa de Educação, tendo sido retirados, com a devida concordância dos autores, da publicação do Ebook da Conferência. No seu conjunto os cinco textos configuram um olhar multifocado a partir de várias escalas de observação e fazendo apelo a uma pluralidade de referenciais teóricos.

A pergunta "A educação ainda é importante para a mobilidade social? Uma perspetiva das desigualdades educacionais da Europa do sul no contexto europeu" orienta a reflexão desenvolvida num artigo da autoria conjunta de Susana da Cruz Martins, Rosário Mauritti, Nuno Nunes, António Firmino da Costa e Ana Lúcia Romão. Esta reflexão apoia-se, em grande medida, na análise longitudinal de dados estatísticos provenientes do European Social Survey (2012), relativos à situação na Europa em geral e aos países do Sul da Europa em particular. Conclui-se que a educação tem efeitos importantes na mobilidade social, nas inserções profissionais e na distribuição de recursos, configurando-se como um elemento estrutural das desigualdades sociais. A análise do caso português no contexto europeu conduz os autores do artigo a destacarem os fortes atrasos educativos e as estruturas sociais muito inigualitárias que continuam a caraterizar o nosso país, sendo estas características pelo menos parcialmente partilhadas com outros países do Sul da Europa.

Também adotando uma perspetiva abrangente, mas focalizada no caso espanhol, no artigo "Crisis de oportunidad para los jóvenes con escasos estudios en España 2005-2014", da autoria de Juan Carlos Solano Lucas e 
Lola Frutos Balibrea, aborda-se o perfil de escolarização da população do país vizinho, analisando em particular a situação dos jovens com baixos níveis de escolaridade. Com base em dados estatísticos nacionais que permitem caracterizar a situação dos jovens em Espanha no decurso da última década, os autores destacam que o contingente de jovens com reduzida escolaridade é, nesse país, tão expressivo como o daqueles que concluíram o ensino superior, correspondendo a um grupo populacional alargado que apresenta vulnerabilidades significativas nos planos social, económico e laboral. Esta característica distintiva do perfil de escolarização dos espanhóis no contexto da OCDE constitui expressão do que os autores designam de "crise de oportunidades", no sentido em que argumentam que, apesar dos avanços conseguidos em democracia, persistem assimetrias educativas e sociais significativas na população espanhola.

É igualmente a temática das trajetórias escolares dos jovens e da relação destes com a escola que é explorada no artigo "Trajetórias escolares e sentidos atribuídos à escola entre a tradição e a modernidade: Perfis de jovens açorianos" da autoria de Ana Matias Diogo, mobilizando informação empírica recolhida nos Açores. A análise de dados desenvolvida pela autora permite evidenciar que a condição dos jovens açorianos não se confunde com a condição de estudante, no sentido em que se identificam contingentes significativos que abandonam precocemente a escola e que protagonizam percursos marcados pelo insucesso escolar. Identifica-se um reconhecimento generalizado do valor da escola entre os jovens açorianos, mas também dificuldades de relação com o trabalho escolar. Nestas condições, os jovens estudantes açorianos polarizam-se entre os que "se encontram em risco de abandono", embora reconhecendo o valor instrumental da escola, e as "empenhadas", maioritariamente raparigas, que investem na escola e aí encontram um espaço de realização pessoal.

Privilegiando o nível de análise meso, o reconhecimento de que a nova gestão pública e a autonomia escolar constituem temas centrais das agendas globais de política educativa constitui o ponto de partida do artigo "Nueva gestión pública y reforma educativa: La recontextualización de la autonomía escolar en diferentes contextos escolares en Cataluña," da autoria de Lluis Parcerisa. Neste cenário, o autor reporta os resultados de uma investigação conduzida na Catalunha, região que afirma ter sido pioneira em Espanha no 
que respeita à implementação deste tipo de políticas educativas. Tendo por base uma pesquisa assente em dois estudos de caso realizados em escolas públicas localizadas numa cidade de média dimensão na Catalunha, o autor conclui pela importância de considerar que as agendas políticas são reinterpretadas em função de contextos escolares específicos. Além disso, assinala possíveis riscos das orientações políticas dominantes associados à redução da democracia interna, à (re)distribuição de poder no interior das escolas com um aumento da relevância da figura do diretor, ao aumento da burocratização e ao agravamento das desigualdades.

Por fim, os professores são objeto de análise no artigo "Professores em Portugal: (Re)posicionamento nas classificações das profissões" de Joana Campos. Mobilizando referências teórico-conceptuais da área da sociologia das profissões, a autora propõe uma reflexão sobre este grupo profissional tendo por base a forma como os profissionais são (re)posicionados e descritos nas classificações de profissões nacionais e internacionais. Concluise que o discurso relativamente disseminado em torno da homogeneização deste grupo profissional tem algum fundamento, nomeadamente quando se considera a sua expressiva feminização, a estatização da atividade docente $e$ a monopolização da tutela como (quase) única entidade empregadora. Não obstante, a autora sustenta que o processo de profissionalização dos professores em Portugal se caracteriza, simultaneamente, pela diferenciação interna, distinguindo-se os professores dos diferentes ciclos e vias de ensino em função de modos específicos de produção e uso do conhecimento profissional, bem como em função das formas de relação com os alunos e suas famílias. Essa dupla tendência de uniformização e diferenciação interna está subjacente ao reposicionamento dos professores nas classificações das profissões, permitindo melhor compreender a etapa atual do processo de profissionalização deste grupo profissional.

Um nota final para agradecer à Direção da Revista Portuguesa de Educação que, desde o primeiro momento, acolheu com interesse a organização deste núcleo temático, o qual é fundamental para ampliar a visibilidade e a projeção dos trabalhos de investigação desenvolvidos no campo da Sociologia da Educação nos dois países ibéricos. Queremos, ainda, agradecer aos autores dos artigos selecionados, às comissões organizadora e científica da conferência, aos revisores científicos e à equipa 
editorial, pelo empenho, profissionalismo e entusiasmo depositado na organização deste núcleo temático.

\section{Referências}

Alves, M. G., Torres, L. L., Dionísio, B., \& Abrantes, P. (Orgs.) (2016). A Educação na Europa do Sul. Constrangimentos e desafios em tempos incertos. Atas da I Conferência Ibérica de Sociologia da Educação. Lisboa: APS. Acesso: http://www.aps.pt/index.php?area=302

Branden, K. V. D., Avermaet, P. V., \& Houtte, M. V. (2011). Equity and excellence in education. Towards maximal learning opportunities for all students. New York: Routledge.

Torres, L. L. \& Palhares, J. A. (2014) (Orgs.). Entre mais e melhor escola em democracia. A inclusão e a excelência no sistema educativo português. Lisboa: Mundos Sociais. 